\title{
Leadership, Compensation Dan Motivation Terhadap Kepuasan Kerja Karyawan Di Hotel Citi International Sun Yat Sen
}

\author{
Juliana1 $^{1}$, Arifin Djakasaputra ${ }^{2}$ \\ ${ }^{1}$ Fakultas Pariwisata, Universitas Pelita Harapan \\ e-mail: juliana.stpph@uph.edu \\ ${ }^{2}$ Fakultas Ekonomi, Universitas Tarumanagara \\ e-mail: arifinds@gmail.com
}

\begin{tabular}{ccc}
\hline Diterima & Direvisi & Disetujui \\
23-10-2019 & 23-01-2020 & $14-02-2020$ \\
\hline
\end{tabular}

\begin{abstract}
Abstrak - Penelitian ini bertujuan untuk menganalisis pengaruh kompensasi, kepemimpinan, dan motivasi yang signifikan terhadap kepuasan kerja. Teknik pengumpulan data menggunakan kuesioner. Hipotesis diuji dengan data primer dengan total sampel 35 responden dikumpulkan melalui kuesioner terstruktur menggunakan metode non probabilitas sampling. Penulis menggunakan kue sioner sebagai metode pengumpulan data, Angket menggunakan Skala Likert seperti 1 (Sangat Tidak Setuju), 2 (Tidak Setuju), 3 (Agak Setuju), 4 (Agak Setuju), 5 (Setuju), 6 (Sangat Setuju). Data dianalisis menggunakan analisis regresi berganda. Hasil analisis menyimpulkan bahwa secara simultan ada pengaruh kepemimpinan, kompensasi, dan motivasi terhadap kepuasan kerja.
\end{abstract}

Kata kunci: kepemimpinan, kompensasi, motivasi, kepuasan kerja

Abstract - This research aims to determine the effect of significant compensation, leadership, and motivation to job satisfaction. Data collection technique is using a questionnaire. The hypotheses were tested with primary data with the total sample 35 respondents collected through structured questionnaire using non probability sampling method. Writer use questionnaire as method of collecting data, The Questionnaire use Likert Scale such as 1 (Strongly Disagree), 2 (Disagree), 3 (Rather Disagree), 4 (Rather Agree), 5 (Agree), 6 (Strongly Agree). Data were analyzed using multiple regression analysis. The results of the analysis concludes that there is simultaneously a leadership effect, compensation , and motivation to job satisfaction.

Keywords :, leadership, compensation, motivation, job satisfaction

\section{PENDAHULUAN}

Pariwisata merupakan salah satu industri yang memberikan kontribusi besar bagi pertumbuhan dunia karena efek gandanya sektor pariwisata dapat menciptakan perubahan yang berkaitan dengan kegiatan sosial, ekonomi dan budaya sehingga dapat memengaruhi perdagangan, investasi, lapangan pekerjaan serta kualitas hubungan antar manusia. Dalam dunia usaha, manusia merupakan sumber daya yang penting untuk mencapai tujuan. Karena manusia berperan dalam menggerakan, mengelola, dan melaksanakan segala aktivitas kegiatan usaha. Oleh karena itu, faktor manusia perlu mendapat mendapat perhatian. Namun manusia sebagai karyawan dalam perusahaan bukanlah hanya sebagai faktor produksi. Melainkan juga sebagai sarana manajemen yang sangat penting, karena manajemen dengan berbagai sumber daya manusia yang tersedia seperti modal, teknologi tidak dapat berjalan tanpa manusia.

Jadi, dalam hal ini pihak manajemen harus melakukan usaha agar dapat meningkatkan kualitas sumber daya manusiannya melalui pengembangan sumber daya manusianya dan memandangnya sebagai aset perusahaan yang harus dikembangkan dengan cara memberi pelatihan, memberikan kompensasi yang layak, menciptakan lingkungan kerja yang baik dan hal-hal lain agar tenaga kerja merasa terpenuhi kebutuhannya sehingga mereka termotivasi untuk dapat bekerja dengan baik dan memiliki semangat yang tinggi dalam melakukan pekerjaannya dan pada akhirnya dapat meningkatkan produktivitas kinerja dari karyawan tersebut Apabila perusahaan dapat memenuhi kebutuhan para karyawannya, maka di dalam diri setiap karyawan tersebut akan timbul suatu kepuasan dalam bekerja yang akan berakibat pada peningkatan produktivitas kerjanya. Setiap karyawan mengharapkan terdapat rasa kepuasan diri dalam benak para karyawan tersebut. Hal ini serupa diharapkan oleh manajer Hotel Citi International Sun Yat Sen bagi karyawannya, karena melalui kepuasan kerja tesebut dapat memengaruhi pola kerja karyawan dalam memberikan kontribusi usaha yang terbaik yang 
dapat diberikannya dalam upaya mencapai prestasi kerja yang baik. Namun dalam hal ini, memotivasi karyawan untuk mewujudkan kepuasan kerja bukanlah merupakan pekerjaan yang mudah untuk dilaksanakan, seperti pula yang dialami oleh manajer Hotel Citi International Sun Yat Sen. Hal ini disebabkan karena adanya perbedaan kebutuhan dari masing-masing karyawan, tidak hanya berbeda dalam kemampuannya dalam menyelesaikan pekerjaan, tetapi juga berbeda dalam kemauan atau dengan kata lain setiap karyawan berbeda antara satu dengan lainnya. Ada karyawan yang bekerja dengan motivasi untuk mengembangkan karir, tetapi ada juga yang memiliki motivasi untuk mendapatkan gaji yang tinggi. Oleh sebab itu, bentuk motivasi antar karyawan juga berbeda satu sama lain. Maka pihak hotel di sini berusaha memotivasi karyawannya dengan cara mencoba untuk memahami persepsi karyawan mengenai apa yang diinginkan dari hotel sebagai perwujudan pemenuhan kebutuhankebutuhan karyawan yang menyangkut sikap mental, perbaikan dan tindakan yang nyata dalam pribadi tenaga kerja itu sendiri. Masalah yang sering dihadapi oleh perusahaan dalam hal kepuasan kerja adalah bagaimana caranya memberikan kompensasi yang terbaik, yaitu sesuai dengan kebutuhan karyawan sehingga para karyawan dapat merasakan kepuasan sehingga dapat berdampak positif bagi perusahaan, sehingga tujuan perusahaan yaitu meningkatkan nilai perusahaan dapat tercapai. Kompensasi merupakan imbalan jasa yang diberikan oleh hotel kepada karyawannya yang telah menyelesaikan pekerjaannya sesuai dengan deksripsi kerja. Hotel Citi International Sun Yat Sen merupakan hotel yang tidak terlalu jauh dari pusat kota,di mana akses sangat mudah dari hotel ini ke sejumlah atraksi dan landmarks seperti Thamrin Plaza, Tirtanadi Water Tower, Pantai Cermin Theme Park. Menurut (Mudor, 2011) menyatakan bahwa kepemimpinan sangat diperlukan bila suatu perusahaan ingin sukses, terlebih lagi karyawan yang baik selalu ingin mengetahui bagaimana karyawan tersebut dapat melaksanakan tugas dan tanggung jawab untuk mencapai tujuan perusahaan. Faktor lain yakni kompensasi juga memengaruhi kepuasan kerja karyawan selain kepemimpinan.Kepemimpinan yang efektif merupakan salah satu aspek yang harus dimiliki oleh seorang manajer yang ingin berhasil (Malik, 2011) Motivasi yang tinggi akan menghasilkan kepuasan kerja yang tinggi sehingga tercermin rasa tanggung jawab dan gairah kerja untuk menciptakan suatu keinginan untuk bekerja dan memberikan seuatu yang baik untuk pekerjaannya. Pentingnya kepuasan kerja menuntut pimpinan perusahaan untuk peka terhadap kepentingan karyawan. Pimpinan perusahaan melakukan pendekatan tidak hanya pada karyawan tetapi juga pada keluarga dan lingkungannya sehingga perusahaan dapat mengetahui apa yang menyebabkan kepuasan kerja karyawan. Menurut (Moorhead \& Griffin, 2013) kepuasan kerja merupakan derajat di mana seseorang puas atau terpenuhi oleh tugas dan tanggung jawabnya. Menurut (Mangkunegara, 2013) motivasi merupakan kondisi yang menggerakkan karyawan agar mampu mencapai tujuan dan motifnya. Compensation menurut (Rivai, 2013) berarti sesuatu yang diterima para karyawan sebagai balas jasa untuk kerja karyawan. Kompensasi dibedakan menjadi dua yakni kompensasi yang bersifat langsung (seperti gaji, upah, bonus, komisi) maupun yang bersifat tidak langsung (seperti asuransi, tunjangan kesehatan, fasilitas untuk karyawan seperti tersedianya seragam, tempat parkir). Kompensasi yang bersifat nonkeuangan lebih mengarah pada penghargaan yang diberikan kepada karyawan atas kemampuan atau kecakapannya dalam bekerja (berkaitan dengan pekerjaan), serta adanya kerabat kerja yang menyenangkan, juga kebijakan-kebijakan yang tepat (seperti diberikannya wewenang kepada karyawan untuk mengambil keputusan dalam memecahkan masalah) sehingga dapat memotivasi karyawan agar mencapai tingkat prestasi yang terbaik (Sulistyowati, 2012) Perumusan masalah dalam penelitian ini apakah terdapat pengaruh positif dan signifikan leadership terhadap kepuasan kerja karyawan? , apakah terdapat pengaruh positif dan signifikan compensation terhadap kepuasan kerja karyawan?, apakah terdapat pengaruh positif dan signifikan motivation terhadap kepuasan kerja karyawan?, apakah terdapat pengaruh positif dan signifikan leadership, compensation dan motivation terhadap kepuasan kerja karyawan?. Tujuan dari penelitian ini untuk menganalisis pengaruh positif dan signifikan leadership, compensation dan motivation terhadap kepuasan kerja karyawan.

Mempertahankan kepuasan kerja atau bahkan meningkatkannya merupakan salah satu tugas penting yang harus dilakukan oleh seorang pemimpin. Penerapan kepemimpinan pada suatu organisasi dengan organisasi lainnya biasanya berbeda-beda, tergantung pada situasi, kondisi kerja, dan jenis pekerjaan yang dilaksanakan.

Pada lazimnya perusahaan menginginkan kepemimpinan yang berorientasi pada produksi tinggi dan hubungan yang tinggi secara bersamaan, di mana produktivitas perusahaan baik menggunakan atau tanpa menggunakan aspek berupa hubungan antara atasan/bawahan yang baik.

Menurut (Yanoto, 2018) menyatakan kepemimpinan (leadership) merupakan kunci bagi organisasi dapat mencapai tujuan sesuai visi dan misi organisasi tersebut. Pemimpin yang dapat menginspirasi dan mengomunikasikan tujuan organisasi dengan baik. Gaya kepemimpinan yang baik akan membuat karyawan merasa puas dalam bekerja di dalam organisasi sesuai dengan penelitian yang dilakukan oleh (Alonderiene, 2016) menyatakan kepemimpinan memiliki pengaruh positif dan signifikan terhadap kepuasan kerja. Kepemimpinan mempunyai pengaruh penting terhadap kepuasan kerja, Tingkat 
kompatibilitas pemimpin dan pekerja merupakan salah satu faktor yang paling penting pada kepuasan kerja. Pemimpin yang memiliki fitur kepemimpinan yang sesuai dengan harapan karyawan lebih disukai karyawan. Pekerja ingin manajer untuk menjadi pemimpin. ketidakpuasan pekerjaan muncul ketika ada kesenjangan antara harapan pekerja terhadap fitur kepemimpinan yang dimiliki manajer. Tingkat kepuasan kerja meningkat ketika kesenjangan antara harapan pekerja mengenai karakteristik kepemimpinan manajer berkurang. Situasi ini menyingkirkan stres kerja yang dialami pekerja

Kompensasi mencakup baik imbalan intrinsik dan imbalan ekstrinsik. Penghargaan ekstrinsik termasuk hadiah moneter dan non moneter. Hadiah uang non moneter mencakup hal-hal selain dari dasar membayar seperti manfaat. Uang adalah indikator motivasi. Kinerja karyawan akan meningkat jika mereka dibayar tinggi. Uang dianggap sebagai imbalan yang diberikan kepada karyawan terhadap pekerjaan, untuk mendukung keluarga mereka, dan pembayaran untuk pekerjaan yang dilakukan. Organisasi harus mempertimbangkan imbalan keuangan seperti gaji karena memiliki pengaruh yang kuat pada motivasi dan retensi karyawan. Gaji karyawan mencakup semua faktor kompensasi yang diberikan kepadanya terhadap karyanya. Gaji merupakan komponen penting untuk retensi karyawan karena jika mereka merasa kesenjangan mengenai upah antara profesi dan lain-lain, mereka dapat puas atau kecewa terhadap pekerjaan mereka. Kurang bayar dibandingkan dengan pekerjaan yang dilakukan merupakan salah satu faktor yang ekstrinsik yang bertanggung jawab untuk pekerjaan ketidakpuasan. Pembayaran memiliki pengaruh langsung terhadap tingkat kepuasan karyawan. Gaji adalah salah satu variabel yang memuaskan dan mengurangi tingkat ketidakpuasan karyawan. Jika seorang karyawan mendapatkan kompensasi sesuai dengan kebutuhannya, ia akan dengan mudah mengelola pekerjaan yang berlebihan jika terjadi keadaan darurat. Misalnya jika gempa datang atau banjir datang dan perawat harus bekerja lembur, mereka dengan senang hati akan melakukannya. Jadi remunerasi adalah faktor yang paling memuaskan (Yaseen, 2013)

Bayaran dan harapan promosi kerja memberikan motivasi yang kuat bagi karyawan untuk bekerja lebih keras agar dapat dipromosikan. Kepuasan searah dengan motivasi. Dalam setiap organisasi, kinerja yang luar biasa adalah mungkin dengan karyawan berkomitmen besar yang hanya dapat dicapai dengan motivasi karyawan. Organisasi menerapkan sistem gaji untuk menghargai karyawan untuk memenuhi tujuan tertentu, yang dapat mempengaruhi tingkat motivasi karyawan. Namun kebanyakan organisasi memperoleh kemajuan sangat pesat dengan sepenuhnya sesuai dengan strategi bisnis mereka melalui penghargaan dan program motivasi yang seimbang untuk karyawan. Dalam lingkungan hidup yang ada karyawan sangat termotivasi memberikan layanan mereka sebagai sinergi untuk pencapaian tujuan organisasi, strategi bisnis, kemampuan tinggi, pertumbuhan dan kinerja Menurut penelitian yang dilaksanakan oleh (Singh, 2011) menyatakan bahwa terdapat korelasi positif antara motivasi dan kepuasan kerja.

Penelitian yang dilakukan oleh (Rachmad, 2013) yang menyimpulkan bahwa: Penelitian ini menemukan bahwa faktor penting yang mempengaruhi komitmen organisasi adalah kepemimpinan dan komunikasi organisasi. Sementara disisi lain komunikasi organisasi dan kepuasan kerja secara bersama-sama merupakan mediator bagi kepemimpinan dalam mempengaruhi komitmen organisasi. Untuk penelitian lebih lanjut diharapkan obyek penelitian dapat diperluas pada seluruh wilayah Indonesia. Penelitian untuk seluruh wilayah Indonesia akan ditemui latar belakang sosial, ekonomi dan budaya yang berbeda sehingga kemungkinan akan terbentuk pola perilaku yang berbeda. Penelitian lebih lanjut juga akan dilaksanakan untuk mengembangkan model dengan melibatkan masyarakat sebagai pengguna jasa perbankan dan mengembangkan variabel-variabel penelitian yang berhubungan dengan masyarakat sebagai konsumen sehingga diperoleh hasil penelitian yang lebih kompleks.

Penelitian yang dilaksanakan oleh (Muttaqien, 2014) menyatakan bahwa leaderhsip dan compensation memiliki pengaruh yang simultan terhadap kepuasan kerja karyawan outsourcing.

Penelitian yang dilakukan oleh (Suryadharma, Adi, Riana, \& Sintaasih, Ketut, 2016) menyatakan bahwa variabel kepemimpinan, kompensasi dan kepuasan kerja karyawan berpengaruh positif dan signifikan terhadap kinerja karyawan.

Penelitian yang dilaksanakan oleh (Juliana \& Djakasaputra, 2019) menyatakan bahwa variabel leadership dan compensation berpengaruh signifikan terhadap job perfomance

Penelitian yang dilakukan (Wardani \& Jacub, 2018) membenarkan bahwa leadership dan financial compesation memiliki pengaruh terhadap kepuasan kerja karyawan.

Penelitian yang dilakukan oleh (Wijayanti, 2013) mengungkapkan bahwa motivasi memiliki pengaruh terhadap kepuasan kerja karyawan

Penelitian yang dilaksanakan oleh (E. Akbar, Mattalatta, 2017) menyatakan bahwa motivasi ,kompensasi serta iklim organisasi berpengaruh positif dan signifikan terhadap kepuasan kerja pegawai pada Dinas Pemuda dan Olahraga Kabupaten Sinjai

Penelitian yang dilaksanakan oleh (Hardiyana \& Fasha Nurhadian, 2016) menyatakan bahwa terdapat pengaruh secara simultan kompensasi dan motivasi terhadap kepuasan kerja karyawan serta implikasinya pada kinerja karyawan. 
Dari hasil penelitian yang relevan dengan penelitian ini maka hipotesis yang dapat dirumuskan meliputi

H1: Terdapat pengaruh positif dan signifikan leadership terhadap kepuasan kerja

H2: Terdapat pengaruh positif dan signifikan compensation terhadap kepuasan kerja

H3: Terdapat pengaruh positif dan signifikan motivation terhadap kepuasan kerja

H4: Terdapat pengaruh positif dan signifikan leadership, compensation dan motivation terhadap kepuasan kerja

Dari hipotesis yang telah dijabarkan dapat dibuat rerangka konseptual

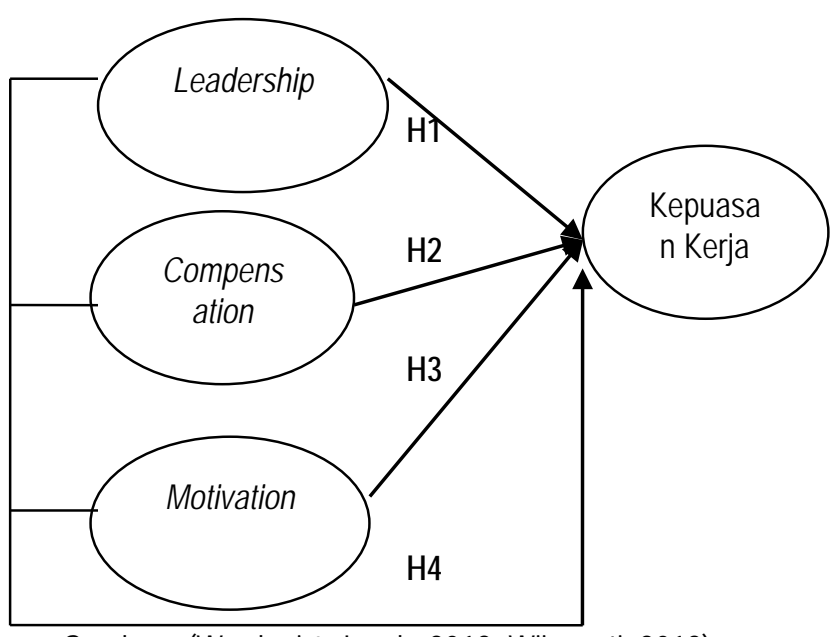

Sumber : (Wardani \& Jacub, 2018; Wijayanti, 2013)

Gambar 1. Rerangka Konseptual

\section{METODE PENELITIAN}

\section{Jenis Penelitian}

Lokasi Penelitian ini ada di Hotel Citi International Sun Yat Sen, Subjek penelitian merupakan karyawan hotel Citi International Sun Yat Sen. Penelitian ini merupakan penelitian kuantitatif. Data yang didapatkan pada penelitian ini berupa angka-angka yang selanjutnya akan dilakukan analisis dan dijabarkan secara deskriptif. Dalam penelitian ini informasi sekunder diperoleh dari berbagai sumber seperti jurnal, data internal dan eksternal dari sumber yang relevan, data Company Profile Hotel Citi International Sun Yat Sen data karyawan yang berhubungan dengan objek penelitian.

\section{Metode Penentuan Sampel}

Metode dalam pemilihan sampel yang digunakan dalam penelitian ini adalah teknik non - Probabilitas yaitu metode convenience sampling. Dalam metode convenience sampling digunakan pengambilan sampel yang dilaksanakan dengan cara dipermudah yaitu dengan cara mendapatkan informasi dari anggota populasi yang tersedia pada saat penelitian berlangsung.(Sekaran,Uma dan Bougie, 2016)
Populasi dalam penelitian ini merujuk pada karyawan Hotel Citi International Sun Yat Sen Sampel dalam penelitian ini berjumlah 35 karyawan Hotel Citi International Sun Yat Sen.

\section{Metode Analisis Data}

Teknik analisis data yang digunakan dalam penelitian ini adalah statistik deskriptif. Selanjutnya penulis melakukan analisis kuantitatif untuk menguji hipotesis yang dirumuskan . Analisis berdasarkan pada variabel leadership,compensation,motivation dan kepuasan kerja. Data yang dianalisis menggunakan skala Likert dengan enam poin (1=sangat tidak setuju, 2=tidak setuju, 3=agak tidak setuju, 4=agak setuju, 5=setuju, 6=sangat setuju). Analisis kuantitatif akan dilakukan dengan bantuan perangkat lunak SPSS versi 23.0 for windows.

Setelah kuesioner dibagikan, diisi dan dikumpulkan, kemudian hasilnya dianalisis dengan menggunakan uji validitas dan reliabilitas serta analisis regresi linier berganda. Uji validitas dan reliabilitas dilakukan untuk menentukan apakah data tersebut layak untuk dianalisis. Kemudian untuk mengetahui instrumen yang digunakan tersebut valid atau tidak, penulis menggunakan validitas internal yang dibantu dengan program komputer, yaitu program SPSS versi 23.0 for windows.

Analisis regresi linier berganda digunakan untuk mengetahui berapa jauh pengaruh dari variabel bebas (independent variable) terhadap variabel tidak bebas (dependent variable). Persamaan regresi linier berganda dalam penelitian ini adalah:

$\mathrm{Y}=\mathrm{a}+\mathrm{b}_{1} \mathrm{X}_{1}+\mathrm{b}_{2} \mathrm{X}_{2}+\mathrm{b}_{3} \mathrm{X}_{3}+\mathrm{e}$

Dimana :

Y : variabel terikat (dependent variabel) yaitu kepuasan kerja karyawan

$$
\begin{aligned}
& \mathrm{a} \quad \text { : nilai intersep (konstanta) } \\
& \mathrm{b} \quad \text { : koefisien regresi linier } \\
& \mathrm{X}_{1} \quad \text { :variabel bebas (independent variabel) } \\
& \text { yaitu leadership } \\
& \mathrm{X}_{2} \quad \text { : variabel bebas (independent variabel) } \\
& \text { yaitu compensation } \\
& \mathrm{X}_{3} \quad \text { : variabel bebas (independent variabel) } \\
& \text { yaitu motivation } \\
& \mathrm{e} \quad \text { : epsilon atau error pada garis regresi, } \\
& \text { merupakan selisih nilai Y yang diprediksikan } \\
& \text { dengan nilai Y yang diperoleh }
\end{aligned}
$$

Uji validitas dan reabilitas merupakan pengujian awal penelitian ini dilanjutkan dengan pengujian hipotesis dilakukan dengan uji t,uji F, kemudian pengujian asumsi klasik dilakukan dengan uji normalitas serta uji multikolinearitas dan uji heteroskedasitas. Uji $\mathrm{F}$ atau dikenal juga dengan ANOVA digunakan untuk mengetahui pengaruh variabel independen terhadap variabel dependen dan menguji apakah model yang dibuat signifikan atau tidak signifikan. Apabila nilai sig $<\alpha$, maka hipotesis ditolak, ini berarti paling sedikit terdapat satu variabel independen yang memiliki pengaruh yang signifikan 
terhadap variabel dependen.Sebaliknya apabila sig $\geq$ $\alpha$, maka hipotesis tidak ditolak, ini berarti tidak terdapat pengaruh yang signifikan dari semua variabel dependen secara bersama-sama terhadap variabel dependen (Sekaran,Uma dan Bougie, 2016)

Uji $\mathrm{t}$ digunakan untuk menguji kebenaran hipotesis yang menyatakan dua atau lebih mean dari kelompok. Pengujian dilakukan dengan menggunakan signifikan level 0,05. Penerimaan dan penolakan hipotesis dilakukan dengan kriteria: Jika nilai signifikan > 0,05 maka hipotesis ditolak (koefisien regresi tidak signifikan). Ini berarti secara parsial variabel independen tidak mempunyai pengaruh signifikan terhadap variabel dependen.

Jika nilai signifikan $<0,05$ maka hipotesis diterima (koefisien regresi signifikan). Ini berarti secara parsial variabel independen tersebut mempunyai pengaruh yang signifikan terhadap variabel dependen (Sekaran dan Bougie,2016 hal.310).

Pengujian koefisien determinasi

bertujuan untuk mengetahui kontribusi dari variabelvariabel independen terhadap variabel dependen

\section{HASIL DAN PEMBAHASAN}

\section{Uji Validitas}

Validitas data untuk masing-masing variabel diukur dengan membandingkan r-hitung dengan rtabel dimana suatu instrumen dinyatakan valid apabila korelasi antara dua skor suatu butir dengan skor totalnya minimal sebesar 0,3. Berikut adalah data hasil output SPSS untuk mencari nilai korelasi antara setiap butir pertanyaan dengan skor totalnya: (Sekaran,Uma dan Bougie, 2016)

Pada tabel 1 terlihat bahwa seluruh indikator pernyataan memiliki nilai korelasi yang lebih besar daripada 0.3 di mana semua indikator dinyatakan valid.

Tabel 1 Hasil Uji Validitas Leadership Item-Total Statistics

\begin{tabular}{|c|c|c|c|c|}
\hline & $\begin{array}{l}\text { Scale } \\
\text { Mean } \\
\text { if } \\
\text { Item } \\
\text { Delete } \\
\text { d }\end{array}$ & $\begin{array}{l}\text { Scale } \\
\text { Varian } \\
\text { ce if } \\
\text { Item } \\
\text { Delete } \\
\text { d }\end{array}$ & $\begin{array}{l}\text { Correcte } \\
\text { d Item- } \\
\text { Total } \\
\text { Correlati } \\
\text { on }\end{array}$ & $\begin{array}{c}\text { Cronbac } \\
\text { h's } \\
\text { Alpha if } \\
\text { Item } \\
\text { Deleted }\end{array}$ \\
\hline $\mathrm{LE}$ & 19.02 & 3.499 & ,359 & ,795 \\
\hline 1 & 86 & & & \\
\hline $\begin{array}{l}\text { LE } \\
2\end{array}$ & $\begin{array}{r}19.40 \\
00\end{array}$ & 3.306 & ,504 & ,750 \\
\hline $\begin{array}{l}\mathrm{LE} \\
3\end{array}$ & $\begin{array}{r}19.34 \\
29\end{array}$ & 2.820 & 660 & 695 \\
\hline $\begin{array}{l}\mathrm{LE} \\
4\end{array}$ & $\begin{array}{r}19.11 \\
43\end{array}$ & 2.987 & 539, & 741 \\
\hline $\begin{array}{l}\text { LE } \\
5\end{array}$ & $\begin{array}{r}19.34 \\
29 \\
\end{array}$ & 2.879 & 709 & 681 \\
\hline \multicolumn{5}{|c|}{$\begin{array}{c}\text { Sumber : Hasil Olahan Data (2017) } \\
\text { Tabel } 2 \text { Hasil Uji Validitas Compensation } \\
\text { Item-Total Statistics } \\
\end{array}$} \\
\hline & $\begin{array}{l}\text { Scale } \\
\text { Mean }\end{array}$ & $\begin{array}{c}\text { Scale } \\
\text { Varian }\end{array}$ & $\begin{array}{c}\text { Correcte } \\
\text { d Item- }\end{array}$ & $\begin{array}{c}\text { Cronbac } \\
\text { h's }\end{array}$ \\
\hline
\end{tabular}

\begin{tabular}{lrccc}
\hline & $\begin{array}{c}\text { if } \\
\text { Item } \\
\text { Delet } \\
\text { ed }\end{array}$ & $\begin{array}{c}\text { ce if } \\
\text { Item } \\
\text { Delete } \\
\text { d }\end{array}$ & $\begin{array}{c}\text { Total } \\
\text { Correlati } \\
\text { on }\end{array}$ & $\begin{array}{c}\text { Alpha if } \\
\text { Item } \\
\text { Deleted }\end{array}$ \\
\hline CO & $\begin{array}{r}23.22 \\
1\end{array}$ & 6.005 & .431 &, 808 \\
CO & $\begin{array}{r}23.51 \\
2\end{array}$ & 6.081 &, 446 &, 803 \\
CO & 23.71 & 5.739 &, 620 &, 766 \\
3 & 43 & & & \\
CO & 23.57 & 5.605 &, 654 &, 759 \\
4 & 14 & & & \\
CO & 23.60 & 5.365 &, 669 &, 753 \\
5 & 00 & & & \\
CO & 23.80 & 5.459 &, 599 &, 770 \\
6 & 00 & & & \\
\hline
\end{tabular}

Sumber : Hasil Olahan Data (2017)

Pada tabel 2 terlihat bahwa seluruh indikator pernyataan memiliki nilai korelasi yang lebih besar daripada 0.3 di mana semua indikator dinyatakan valid

Tabel 3 Hasil Uji Validitas Motivation Item-Total Statistics

\begin{tabular}{|c|c|c|c|c|}
\hline & $\begin{array}{l}\text { Scale } \\
\text { Mean } \\
\text { if } \\
\text { Item } \\
\text { Delet } \\
\text { ed } \\
\end{array}$ & $\begin{array}{l}\text { Scale } \\
\text { Varian } \\
\text { ce if } \\
\text { Item } \\
\text { Delete } \\
\text { d } \\
\end{array}$ & $\begin{array}{l}\text { Correcte } \\
\text { d Item- } \\
\text { Total } \\
\text { Correlati } \\
\text { on }\end{array}$ & $\begin{array}{l}\text { Cronbac } \\
\text { h's } \\
\text { Alpha if } \\
\text { Item } \\
\text { Deleted }\end{array}$ \\
\hline $\mathrm{MO}$ & 18.48 & 2.434 & ,321 & ,661 \\
\hline 1 & 57 & & & \\
\hline $\begin{array}{l}\text { MO } \\
2\end{array}$ & $\begin{array}{r}18.71 \\
43\end{array}$ & 2.445 & ,341 & 591 \\
\hline $\begin{array}{l}\text { MO } \\
3\end{array}$ & $\begin{array}{r}18.80 \\
00\end{array}$ & 2.165 & 448 & ,537 \\
\hline $\begin{array}{l}\mathrm{MO} \\
4\end{array}$ & $\begin{array}{r}18.54 \\
29\end{array}$ & 2.079 & 455, & 531 \\
\hline $\begin{array}{l}\mathrm{MO} \\
5\end{array}$ & $\begin{array}{r}18.71 \\
43\end{array}$ & 2.151 & 471 & ,526, \\
\hline
\end{tabular}

Sumber : Hasil Olahan Data (2017)

Pada tabel 3 terlihat bahwa seluruh indikator pernyataan memiliki nilai korelasi yang lebih besar daripada 0.3 di mana semua indikator dinyatakan valid

Tabel 4 Hasil Uji Validitas Kepuasan Kerja Item-Total Statistics

\begin{tabular}{lrrrr}
\hline & $\begin{array}{c}\text { Scale } \\
\text { Mean } \\
\text { if } \\
\text { Item } \\
\text { Delet } \\
\text { ed }\end{array}$ & $\begin{array}{c}\text { Scale } \\
\text { Varian } \\
\text { ce if } \\
\text { Item } \\
\text { Delete } \\
\text { d }\end{array}$ & $\begin{array}{c}\text { Correcte } \\
\text { d Item- } \\
\text { Total } \\
\text { Correlat } \\
\text { ion }\end{array}$ & $\begin{array}{c}\text { Cronbac } \\
\text { h's } \\
\text { Alpha if } \\
\text { Item } \\
\text { Deleted }\end{array}$ \\
\hline KE & $\begin{array}{r}33.42 \\
\text { K1 }\end{array}$ & 14.782 &, 427 &, 894 \\
KE & 33.22 & 12.887 &, 699 &, 868 \\
K2 & 86 & & & \\
KE & 33.28 & 12.622 &, 818 &, 855 \\
K3 & 57 & & & \\
KE & 33.51 & 14.198 &, 528 &, 885 \\
K4 & 43 & & & \\
KEK & 33.54 & 13.667 &, 516 &, 889 \\
5 & 29 & & & \\
KEK & 33.37 & 13.182 &, 815 &, 858 \\
6 & 14 & & &
\end{tabular}




\begin{tabular}{lrrrr} 
KEK & 33.34 & 13.467 &, 765 &, 863 \\
7 & 29 & & & \\
KEK & 33.28 & 13.622 &, 775 &, 863 \\
8 & 57 & & & \\
\hline
\end{tabular}

Sumber : Hasil Olahan Data (2017)

Pada tabel 4 terlihat bahwa seluruh indikator pernyataan memiliki nilai korelasi yang lebih besar daripada 0.3 di mana semua indikator dinyatakan valid

\section{Uji Reliabilitas}

Uji realibilitas dapat dilihat dengan memenggunakan cronbach alpha (Sekaran,Uma dan Bougie, 2016) Jika cronbach alpha $>0.6$, maka dapat dikatakan reliabel atau konsisten.

Tabel 5. Hasil Uji Reliabilitas

\begin{tabular}{cccc}
\hline Variabel & $\begin{array}{c}\text { Cronbach's } \\
\text { Alpha }\end{array}$ & $\begin{array}{c}\text { N of } \\
\text { items }\end{array}$ & Keterangan \\
\hline Leadership & 0.777 & 5 & Reliabel \\
Compensation & 0.807 & 6 & Reliabel \\
Motivation & 0.626 & 5 & Reliabel \\
Kepuasan & 0.887 & 8 & Reliabel \\
Kerja & & & \\
\hline
\end{tabular}

Sumber : Hasil Olahan Data (2017)

Berdasarkan Tabel 5 diatas dapat dilihat hasil uji reliabilitas terhadap 92 responden dan didapat bahwa nilai cronbach's alpha untuk variabel leaderhsip $(\mathrm{X} 1)=0,763$, variabel compesation $(\mathrm{X} 2)=0,862$, variabel motivation $(\mathrm{X} 3)=0,863$ dan variabel kepuasan kerja $(\mathrm{Y})=0,944$ Kesemua variabel tersebut memiliki nilai cronbach's alpha diatas 0,600. Ini berarti bahwa variabel X1, X2, X3 dan Y tersebut telah memenuhi kriteria nilai batas dan dapat dinyatakan reliabel serta layak untuk disebarkan kepada responden guna penelitian.

\section{Deskripsi Subjek Penelitian}

Dalam penelitian ini populasi merupakan karyawan hotel Citi International Sun Yat Sen Metode pengambilan data yang digunakan adalah metode survey langsung ke hotel Citi International Sun Yat Sen. Metode survei ini melalui cara datang langsung ke lapangan dengan disertai menyebarkan kuesioner yang telah disusun oleh penulis dan data yang tertulis maupun tidak tertulis yang didapatkan dari hotel Citi International Sun Yat Sen. Data tersebut meliputi data skor leadership, compensation, motivation, dan kepuasan kerja karyawan. Adapun data yang didapatkan melalui metode di atas adalah sebagai berikut:

Tabel 6 Deskripsi Subjek Penelitian

\begin{tabular}{ccc}
\hline Karakteristik & Kriteria & Jumlah \\
\hline Jenis & Laki-Laki & 20 \\
Kelamin & Perempuan & 15 \\
\hline Tingkat & SMK & 15 \\
Pendidikan & Diploma & 8 \\
\hline
\end{tabular}

\begin{tabular}{ccc}
\hline & S1 & 5 \\
& Lain-Lain & 7 \\
\hline Usia & $<30$ tahun & 17 \\
& $31-40$ tahun & 10 \\
& $41-50$ tahun & 5 \\
& $>50$ tahun & 3
\end{tabular}

Sumber : Hasil Olahan Data (2017)

\section{Koefisien Determinasi $\left(\mathbf{R}^{2}\right)$}

Tabel 7 Hasil Uji Koefisien Determinasi $\left(\mathrm{R}^{2}\right)$

\begin{tabular}{ccccc}
\hline Model & $\mathrm{R}$ & $\begin{array}{c}\mathrm{R} \\
\text { Square }\end{array}$ & $\begin{array}{c}\text { Adjusted } \\
\text { R Square }\end{array}$ & $\begin{array}{c}\text { Std.Error } \\
\text { of the } \\
\text { Estimate }\end{array}$ \\
\hline $\mathbf{1}$ & .961 & .923 & .915 & 1.3055 \\
\hline Sumber :Hasil Olahan Data (2017)
\end{tabular}

Setelah melakukan tabulasi dengan program spss, hasil yang didapatkan dari koefisien determinasi $\left(\mathrm{R}^{2}\right)$ sebesar 0.923 Hal ini menunjukkan bahwa leadership,compensation,motivation terhadap kepuasan kerja sebesar 92.3\% dan sisanya dapat dijelaskan oleh variable lainnya diluar penelitian

\section{Uji F}

Hasil uji $\mathrm{F}$ ini dapat dilihat dengan membandingkan $\mathrm{F}_{\text {hitung }}$ dengan $\mathrm{F}_{\text {tabel, }}$ jika $\mathrm{F}_{\text {hitung }}>\mathrm{F}$ tabel maka model signifikan sedangkan jika $\mathrm{F}_{\text {hitung }}<\mathrm{F}$ tabel maka model tidak signifikan.

Dengan Level of Significant $\alpha=5 \%, \mathrm{n}=3{ }^{\mathrm{N}}$, df1 = 3 dan $\mathrm{df} 2=31$, berdasarkan hasil analisis SPSS yang disajikan pada Tabel 8 didapat nilai F-hitung $>$ Ftabel dan sig. sebesar 0,00 yang artinya sig $<0,05$. Oleh karena itu variabel leadership.compensation dan motivation berpengaruh positif dan signifikan terhadap kepuasan kerja karyawan berarti menolak $\mathrm{H}_{0}$ dan menerima $\mathrm{H}_{1}$.

Tabel 8. Uji F (ANOVA)

\begin{tabular}{|c|c|c|c|c|c|}
\hline Model & $\begin{array}{l}\text { Sum of } \\
\text { Squares }\end{array}$ & Df & $\begin{array}{l}\text { Mean } \\
\text { Squa } \\
\text { re }\end{array}$ & $\mathbf{F}$ & Sig \\
\hline Regression & 6.311 & 3 & 2.104 & 123.426 & $.000^{\mathrm{b}}$ \\
\hline Residual & .528 & 31 & 0.17 & & \\
\hline Total & 6.839 & 34 & & & \\
\hline
\end{tabular}

a.Predictors:(Constant),Leadership.compensation, motivation

b. Dependent Variable: Kepuasan

Sumber : Hasil Olahan Data (2017)

\section{Uji t}

Uji t dapat juga dilakukan dengan membandingkan hasil thitung dan tabel dengan signifikansi level 0,05 ( $\alpha=5 \%$ ). Nilai dari uji t-test dapat dilihat dari p-value (pada kolom Sig.) pada masing-masing variabel bebas (Sekaran,Uma dan Bougie, 2016) Pengujian ini dimaksudkan untuk menganalisis apakah leadership,compensation serta motivation secara parsial memiliki pengaruh yang signifikan terhadap kepuasan kerja karyawan Hotel Citi Internasional Sun Yat Sen. 
Tabel 9. Uji t

\begin{tabular}{cccccc}
\hline Model & $\begin{array}{c}\text { Unstandardized } \\
\text { Coefficients }\end{array}$ & $\begin{array}{c}\text { Standardize } \\
\mathbf{d} \\
\end{array}$ & \multicolumn{5}{c}{$\begin{array}{c}\text { t } \\
\text { Coefficients }\end{array}$} & Sig \\
\cline { 2 - 6 } & $\mathrm{B}$ & Std. Error & Beta & & \\
(Constant) & 1.253 & .308 & & .823 & .417 \\
$L E$ & .127 & .072 & .133 & 1.774 & .086 \\
$C O$ & .861 & .087 & .822 & 5.902 & .000 \\
$M O$ & .068 & .081 & .055 & .847 & .403 \\
\hline
\end{tabular}

Sumber : Hasil Olahan Data (2017)

\section{Analisis Regresi Berganda}

Analisis regresi memiliki tujuan untuk dipergunakan dalam suatu situasi dimana hipotesis dari satu independen variabel memengaruhi satu dependen variabel. (Sekaran,Uma dan Bougie, 2016) Dari hasil perhitungan analisis regresi berganda didapatkan persamaan sebagai berikut :

$\mathrm{Y}=\alpha+\beta 1 \mathrm{X} 1+\beta 2 \mathrm{X} 2+\beta 3 \mathrm{X} 3+e$

$\mathrm{Y}=1.253+0,127 \mathrm{X} 1+0.861 \mathrm{X} 2+0,68 \mathrm{X} 3+\mathrm{e}$

Berdasarkan persamaan di atas maka dapat diinterpretasikan bahwa

Nilai a $=1.253$ konstanta sebesar 1.253 bahwa variabel kepuasan kerja karyawan sebesar 1.253 apabila score variabel independen sama dengan nol Nilai X1 sebesar 0.127 merupakan penaksir parameter variabel leadership menunjukkan apabila nilai leadership meningkat 1 satuan, maka kepuasan kerja karyawan akan meningkat sebesar 0.127 satuan dengan asumsi tidak ada faktor lain yang memengaruhinya.

Nilai X2 sebesar 0.861 merupakan penaksir parameter variabel compensation menunjukkan apabila nilai compensation meningkat 1 satuan, maka kepuasan kerja karyawan akan meningkat sebesar 0.861 satuan dengan asumsi tidak ada faktor lain yang memengaruhinya.

Nilai X3 sebesar 0.68 merupakan penaksir parameter variabel motivation menunjukkan apabila nilai motivation meningkat 1 satuan, maka kepuasan kerja karyawan akan meningkat sebesar $0 . .68$ satuan dengan asumsi tidak ada faktor lain yang memengaruhinya.

\section{Analisa dan Pembahasan}

Penelitian ini menunjukkan hasil untuk ketiga hipotesis adalah sebagai berikut:

Berdasarkan hasil analisis data dan pengujian hipotesis dapat disimpulkan bahwa terdapat pengaruh yang signifikan dan positif leadership,compensation dan motivation terhadap kepuasan kerja. Hal ini sesuai dengan penelitian yang dilaksanakan oleh (Wijayanti, 2013) menyatakan bahwa motivation berpengaruh positif terhadap kepuasan kerja pada karyawan KPRI Pertaguma Kota madiun dimana motivasi dari dalam diri individu yang tinggi akan mengakibatkan kepuasan kerja juga meninggakt serta penelitian yang dilaksanakan oleh (Wardani \& Jacub,
2018) menyatakan bahwa kepemimpinan berpengaruh signifikan terhadap kepuasan kerja yang menunjukkan bahwa kepemimpinan seseorang individu berpengaruh dalam meningkatkan kepuasan kerja karyawan serta kompensasi finansial berpengaruh signifikan terhadap kepuasan kerja yang menunjukkan hubungan searah dalam arti kompensasi finansial berpengaruh dalam rifel9ngkatkan kepuasan kerja karyawan.

.000 Tabel 10 Hasil Penelitian

.000

Hipotesis Uji $\quad$ Uji t Hasil
Reliablita

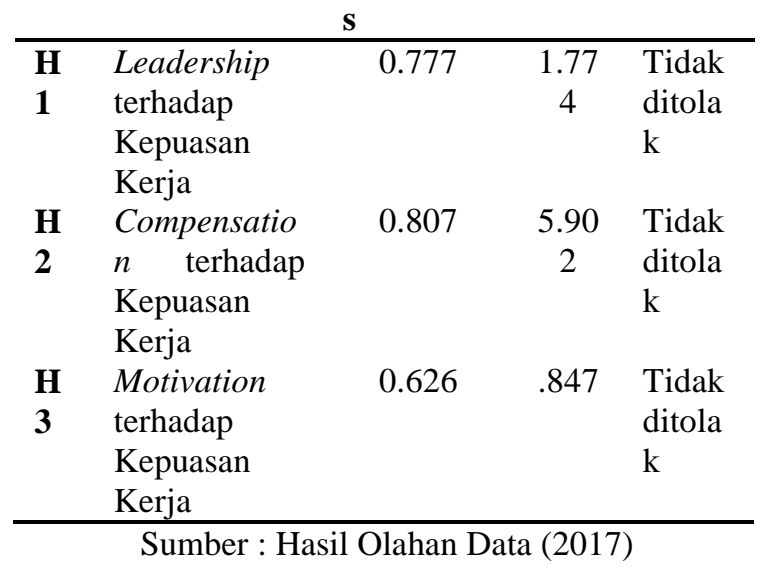

\section{KESIMPULAN}

Berdasarkan hasil analisis dan pembahasan mengenai pengaruh leadership, compensation dan motivation terhadap kepuasan kerja karyawan hotel Citi International Sun Yat Sen dapat dibuat simpulan sebagai berikut

a. Terdapat pengaruh positif dan signifikan leadership terhadap kepuasan kerja. Artinya semakin baik leadership yang diberikan maka semakin tinggi kepuasan kerja.

b. Terdapat pengaruh positif dan signifikan compensation terhadap kepuasan kerja. Artinya pemberian compensation yang adil dan merata dapat meningkatkan kepuasan kerja.

c. Terdapat pengaruh positif dan signifikan motivation terhadap kepuasan kerja. Artinya karyawan yang termotivasi dengan baik akan meningkatkan kepuasan kerjanya.

d. Terdapat pengaruh leadership, compensation dan motivation terhadap kepuasan kerja. Artinya leadership, compensation dan motivation yang baik mampu meningkatkan kepuasan kerja.

Implikasi praktis dan implikasi teoritis bahwa untuk peneliti selanjutnya yang mengangkat topik sejenis diharapkan dapat menambah variabel atau indikator lainnya yang belum dimasukkan dalam penelitian ini. Penelitian ini memiliki keterbatasan generalisasi, keterbatasan waktu, keterbatasan tenaga di mana penelitian ini hanya dilakukan di satu wilayah yaitu daerah Medan Setelah menganalisis permasalahan yang terdapat pada Hotel Citi 
International Sun Yat Sen maka saran yang dapat diberikan adalah agar hotel Citi International Sun Yat Sen dapat meningkatkan kepuasan kerja karyawan dengan memperhatikan peningkatan pemberian compensation, menciptkan iklim kerja yang kondusif, serta motivasi yang menggairahkan semangat kerja karyawan

\section{REFERENSI}

Alonderiene, R. dan M. (2016). Leadership style and job satisfaction in higher education institutions. International Journal of Educational Management, v30 n1, p140-164 2016.

E. Akbar, Mattalatta, G. (2017). Pengaruh Motivasi, Kompensasi Dan Iklim Organisasi Terhadap Kepuasan Kerja Pegawai Dinas Pemuda Dan Olahraga Kabupaten Sinjai. Jurnal Mirai Management, 2(2), 257-269.

Hardiyana, A., \& Fasha Nurhadian, A. (2016). Pengaruh Kompensasi Dan Motivasi Kerja Terhadap Kepuasan Kerja Serta Implikasinya Pada Kinerja Karyawan. Jurnal Ekonomi, Bisnis \& Entrepreneurship, 10(2), 104-118.

Hasibuan, M. (2010). Manajemen Sumber Daya Manusia. Bumi Aksara. Jakarta.

Juliana \& Djakasaputra, A. (2019). Leadership dan Compensation terhadap Job Performance Karyawan Swiss-Belinn Hotel Medan. 17(2), 157-162.

L. Mathis, Robert dan H. Jackson, J. (2011). Human Resource Management (Edisi 10). Jakarta: Salemba Empat.

Malik. (2011). Member satisfaction factors working at the University of Balochistan. Internasional. Journal of Balochistan University Pakistan.

Mangkunegara, A. (2013). Manajemen Sumber Daya Manusia Perusahaan. Bandung.

Moorhead, G., \& Griffin, R. W. (2013). Perilaku Organisasi Manajemen Sumber Daya Manusia dan Organisasi (Diana Angelica, Penerjemah.). In Jakarta: Penerbit Salemba Empat. https://doi.org/https://doi.org/10.3929/ethz-b000238666

Mudor. (2011). The relationship between human resource management practices,turnover and job satisfaction. Internasional Journal of Songkla University Thailand.

Muttaqien, F. (2014). Pengaruh Kepemimpinan Dan Kompensasi Terhadap Kepuasan. Jurnal WIGA, 4(1), 19-33.

Rachmad, H. (2013). Pengaruh Kepemimpinan terhadap Komunikasi, Kepuasan Kerja, dan Komitmen Organisasi pada Industri Perbankan. Makara Seri Sosial Humaniora.

Rivai, V. (2013). Manajemen Sumber Daya Manusia
Untuk Perusahaan. Jakarta: Raja Grafindo Persada.

Robbins, \& Coulter, M. (2014). Management (12th Ed). In Prentice Hall. https://doi.org/10.1002/15213773(20010316)40:6<9823::AIDANIE9823>3.3.CO;2-C

Sekaran,Uma dan Bougie, R. (2016). (2016). Research Methods for Business (7th editio). John Wiley \& Sons Limited.

Singh. (2011). Relationship Between Motivation and Job Satisfaction of The White Collar Employee. Research Scholar, Faculty of Management Studies, Banaras Hindu University, Varanasi, Vol. VII,.

Sulistyowati, D. (2012). Analisis Faktor-Faktor Yang Mempengaruhi Pencapaian Target Kinerja Individu Perawat Pelaksana Berdasarkan Indeks Kinerja Individu Di Gedung A Rumah Sakit Umum Pusat Nasional DR. Cipto Mangunkusumo. Universitas Indonesia,Jakarta.

Suryadharma, Adi, M., Riana, G., \& Sintaasih, Ketut, D. (2016). Pengaruh Kepemimpinan Dan Kompensasi Terhadap Kepuasan Kerja Dan Kinerja Karyawan (Studi Pada Pt. Bpr Sri Artha Lestari Denpasar). E-Jurnal Ekonomi Dan Bisnis Universitas Udayana, 2, 335-358.

Sutrisno, E. (2010). Budaya Organisasi. Jakarta: Kencana.

Wardani, D., \& Jacub, F. F. (2018). Analisis Pengaruh Kepemimpinan Dan Kompensasi Finansial Terhadap Kepuasan Kerja Karyawan. Jurnal Ilmu Manajemen \& Ekonomika, 8(1), 18. https://doi.org/10.35384/jime.v8i1.91

Wijayanti, D. P. (2013). Pengaruh Motivasi Terhadap Kepuasan Kerja Pada Karyawan Kpri "Pertaguma” Kota Madiun. EQUILIBRIUM: Jurnal Ilmiah Ekonomi Dan Pembelajarannya, 1(2), 199-206. https://doi.org/10.25273/equilibrium.v1i2.608

Yanoto, A. (2018). Pengaruh Gaya Kepemimpinan Terhadap Kepuasan Kerja Melalui Motivasi dan Kinerja Karyawan PT. Nutrifood Indonesia di Surabaya. Agora, 6(1).

Yaseen, A. (2013). Effect of Compensation Factors on Employee Satisfaction- A Study of Doctor's Dissatisfaction in Punjab. International Journal of Human Resource Studies, 3(1), 142. https://doi.org/10.5296/ijhrs.v3i1.3351 1(2),199-206. https://doi.org/10.25273/equilibrium.v1i2.608 